\title{
Prevalencia de pseudohipercaliemia en pacientes con enfermedad renal crónica en terapia hemodialítica
}

\section{Prevalence of pseudohyperkalemia in patients with chronic renal disease in hemodialysis therapy}

\author{
María Fernanda Sanint, Gilberto Manjarrés, César A. Restrepo • \\ Manizales (Colombia)
}

\section{Resumen}

Objetivo: determinar si a la hipercaliemia prolongada en pacientes en hemodiálisis con enfermedad renal crónica (ERC) contribuye en valor significativo la presencia de pseudohipercaliemia (diferencia entre potasio sérico a plasmático mayor a $0.5 \mathrm{mEq} / \mathrm{L}$ )

Pacientes: aquellos con ERC en terapia hemodialítica por mas de 12 meses de evolución en quienes se detectara hipercaliemia persistente por más de tres meses.

Material y métodos: determinación simultánea de potasio sérico y plasmático, y adicionalmente las variables sodio sérico, gases arteriales, cuadro hemático completo, glucemia en ayunas, Kt/v y electrocardiograma

Resultados: en 110 pacientes evaluados 17 cumplieron los criterios de inclusión, en ellos en 13 (76.47\%) se detectó pseudohipercaliemia y en 4 (23.52\%) hipercaliemia verdadera (diferencia entre potasio sérico a plasmático menor a $0.5 \mathrm{mEq} / \mathrm{L}$ ). No se detectaron diferencias significativas entre grupos en las variables analizadas

Conclusión: la pseudohipercaliemia representa un porcentaje muy importante del reporte de hipercaliemias en pacientes con ERC en terapia hemodialítica, y lo ideal en ellos es siempre determinar potasio plasmático. (Acta Med Colomb 2013; 38: 12-15)

Palabras clave: hipercaliemia, potasio sérico, potasio plasmático, pseudohipercaliemia

\footnotetext{
Abstract

Objective: determine if to prolonged hyperkalemia in hemodialysis patients with chronic kidney disease (CKD) contributes significantly the presence of pseudohyperkalemia (difference between serum to plasma potassium greater than $0.5 \mathrm{mEq} / \mathrm{L}$ )

Patients: those with CKD on hemodialysis therapy for more than 12 months duration in whom persistent hyperkalemia is detected for more than three months.

Materials and methods: simultaneous determination of serum and plasma potassium and in addition the variables serum sodium, arterial blood gases, complete blood count, fasting blood glucose, $\mathrm{Kt} / \mathrm{v}$ and electrocardiogram

Results: in 110 patients evaluated 17 met the inclusion criteria. In 13 of them $(76.47 \%)$ we detected pseudohyperkalemia and in $4(23.52 \%)$ true hyperkalemia (difference between serum to plasma potasium less than $0.5 \mathrm{mEq} / \mathrm{L}$ ). No significant differences between groups in the variables analyzed were detected.

Conclusion: the pseudohyperkalemia represents a very important percentage of the report of hiperkalemias in CKD patients on hemodialysis therapy, and ideally plasma potasium has to be determined always in these patients. (Acta Med Colomb 2013; 38: 12-15).

Keywords: hyperkalemia, serum potassium, plasma potassium, pseudohiperkalemia.
}

Dra. María Fernanda Sanint Gonzales: Nutricionista Dietista; Dr. Gilberto Manjarrés Iglesias: Internista, Profesor Asistente Universidad de Caldas; Dr. César A. Restrepo Valencia: Internista Nefrólogo, Profesor Asociado Universidad de Caldas. Manizales (Colombia).

Correspondencia. Dr. César A. Restrepo V. E-mail: caugustorv@une.net.co Recibido: 2/VI/2012 Aceptado: 25/I/2013 


\section{Introducción}

En el valor sanguíneo del potasio participan diversos factores: aporte oral o parenteral, redistribución transcelular, y eliminación renal y extrarrenal. En pacientes con enfermedad renal crónica (ERC) en terapia dialítica el potasio sérico es un parámetro que evalúa la eficacia de dicha terapia, y la adherencia del paciente a sus recomendaciones nutricionales. Hipercaliemia se define por un valor sérico mayor a $5.5 \mathrm{mEq} / \mathrm{L}$, y en el diagnóstico diferencial de su etiología se debe incluir siempre la pseudohipercaliemia (1), entidad caracterizada por elevación del potasio sólo en suero (sobrenadante de la sangre coagulada) debido a la liberación de potasio de las células contenidas en el coágulo, sin que se presente esta alteración cuando el potasio se determina en muestras plasmáticas (sangre centrifugada, con estudio del potasio en el sobrenadante). En los pacientes con ERC se ha sugerido que el medio urémico predispone a fragilidad de los glóbulos rojos, en forma tal que en muestras almacenadas para determinación del potasio sérico puede generarse liberación importante de potasio, lo cual puede dar lugar a pseudohipercaliemia $(2,3)$. Con el fin de establecer si la pseudohipercaliemia representa un trastorno importante en pacientes con ERC en terapia dialítica, impactando en las conductas terapéuticas que a ellos se aplican se llevó a cabo este estudio sobre una población de pacientes en los cuales fue común detectar valores permanentemente altos de potasio sérico en los últimos controles mensuales.

\section{Material y métodos}

Pacientes con ERC en terapia hemodialítica durante mínimo un año, estables hemodinámicamente, sin patología aguda en el momento de su evaluación.

\section{Criterios de inclusión}

Pacientes quienes en el curso de los últimos tres meses hubiesen presentado valores persistentemente altos considerados en rango de hipercaliemia (mayores a $5.5 \mathrm{mEq} / \mathrm{L}$ ), a pesar de darles recomendaciones de llevar dieta baja en potasio (menor a $0.5 \mathrm{mEq}$ (19.5 miligramos $/ \mathrm{kg} / \mathrm{día}$ ), ausencia de historia familiar de hipercaliemia, pseudohipercaliemia familiar, estomatosis hereditaria deshidratada, criohidrocitosis y xerositosis hereditaria, fístula arteriovenosa funcional y que permitiera un flujo sanguíneo mayor de $300 \mathrm{~mL} / \mathrm{minuto}$.

\section{Criterios de exclusión}

Antecedentes de ayuno prolongado, acidosis metabólica predialítica (bicarbonato sérico menor a $20 \mathrm{mEq} / \mathrm{L}$ ), desórdenes mieloproliferativos, uso de manitol intravenoso y administración de medios de contraste ocho días previos al estudio. Se incluyeron en la lista de medicamentos con potencial capacidad de generar hipercaliemia, pero que no fue posible su suspensión por indicación médica: digital, IECA, ARA II, espironolactona, B-bloqueadores, AINES y minoxidil (activa los canales de K dependientes de ATP-asa).
Se definió pseudohipercaliemia a la diferencia del potasio sérico sobre el plasmático superior a $0.5 \mathrm{mEq} / \mathrm{L}$, e hipercaliemia verdadera a una diferencia menor a $0.5 \mathrm{mEq} / \mathrm{L}$.

Para el estudio se tomó una muestra sanguínea con un volumen total de $15 \mathrm{~mL}$, distribuido así: $5 \mathrm{~mL}$ de sangre en tubo con citrato para obtención de plasma, $5 \mathrm{~mL}$ para generar suero, y $3 \mathrm{~mL}$ de sangre con EDTA para determinación de pruebas hematológicas (hemoleucograma completo), nitrógeno ureico y glucemia, así como una muestra de 0.5 $\mathrm{mL}$ de sangre arterial para el análisis de $\mathrm{pH}$ y gases arteriales. El procesamiento de las muestras fue llevado a cabo en todas las situaciones en un tiempo inferior a una hora después de tomadas las muestra. Para la determinación del potasio plasmático $5 \mathrm{~mL}$ de sangre fueron centrifugados a 2000 revoluciones por minuto durante cinco minutos. Para cuantificar potasio sérico $5 \mathrm{~mL}$ de la muestra sanguínea fueron permitidos que se coagularan en tubo de ensayo sin gel procoagulante durante 30 minutos (para permitir una adecuada retracción del coágulo) a temperatura ambiente, y luego centrifugación durante cinco minutos a 2000 revoluciones por minuto (Figura 1). El potasio se determinó en sangre y plasma por electrodo selectivo de iones.

Se evitó el ejercicio vigoroso del brazo, tanto previo como durante la toma de la muestra.

Las muestras sanguíneas para estudio simultáneo de potasio sérico y plasmático se tomaron inmediatamente antes de la hemodiálisis, lo más cercana posible al sitio de la anastomosis arteriovenosa, sin torniquetes, y sin que el paciente practicara la maniobra de cerrar y abrir el puño. Al finalizar la sesión de hemodiálisis se tomó una última muestra para poder calcular el $\mathrm{Kt} / \mathrm{v}$, fórmula matemática que evalúa la eficacia de la terapia dialítica por medir el porcentaje de urea retirada durante la misma. Se recolectó luego la orina en un periodo de 42 horas con el fin de estimar la función renal residual (FRR).

Se analizaron las variables sexo, edad, etiología de enfermedad renal crónica, consumo de medicamentos que pudieran generar hipercaliemia, potasio sérico, potasio plasmático, sodio sérico, $\mathrm{pH}$ arterial, bicarbonato plasmático, hemoglobina, conteo leucocitario, conteo plaquetario, glucemia en ayunas y Kt/v. Por interrogatorio estricto se calculó el consumo diario de potasio. En el momento de la toma de los exámenes se practicó electrocardiograma con el fin de establecer si se presentaban hallazgos compatibles con hipercaliemia. De acuerdo con los resultados los pacientes se incluyeron en dos grupos: Grupo A pseudohipercaliemia, Grupo B hipercaliemia real.

\section{Resultados}

En la Universidad de Caldas se evaluaron 110 pacientes en terapia hemodialítica, de ellos 17 pacientes cumplieron los criterios de inclusión. En 13 (76.47\%) pacientes se encontró pseudohipercaliemia, en cuatro $(23.52 \%)$ pacientes hipercaliemia verdadera. El consumo estimado de potasio oral fue cercano a 1780 miligramos en los dos grupos, lo 
cual demostró poca adherencia a la dieta, en la comparación de variables entre los dos grupos se encontró que en el grupo con hipercaliemia verdadera había valores ligeramente mas altos de glucemia en ayunas, Kt/v, tiempo en diálisis, y menores de hemoglobina; sin embargo, las diferencias no fueron estadísticamente significativas con estas variables ni con las otras analizadas (Tabla 1). En los dos grupos el pH sanguíneo y bicarbonato plasmático estuvieron en valores esperados para un estado predialítico, sin detectarse acidosis metabólica que pudiese explicar la hipercaliemia. Tampoco se detectó hiperglucemia, ni hipernatremia, alteraciones que al aumentar la osmolaridad plasmática podrían alterar los valores de potasio sanguíneo. El conteo leucocitario y plaquetario fue normal, lo que excluyó la presencia de hipercelularidad. En el electrocardiograma en ninguno de los grupos se presentó hallazgos compatibles con hipercaliemia.

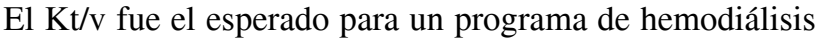
descartándose la subdialisis.

\section{Discusión}

En la aparición de hipercaliemia en pacientes en terapia dialítica intervienen diversos factores: adherencia a la dieta, eficacia de la terapia dialítica, medicamentos y constipación. Una vez intervenido el componente nutricional, evaluando por interrogatorio el consumo aproximado de potasio diario, se debe posteriormente analizar la eficiencia de la terapia

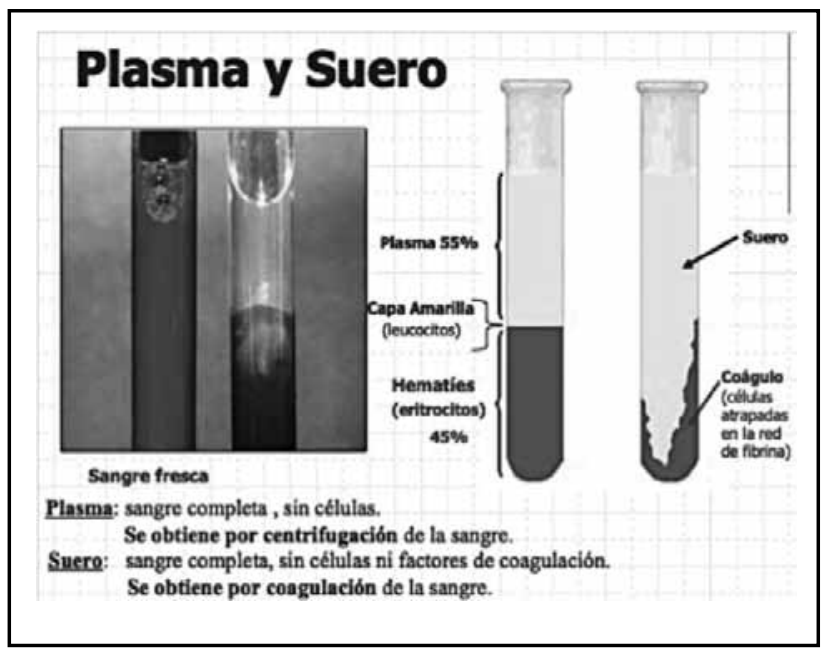

Figura 1. Diferencias entre plasma y suero.

hemodialítica calculando el Kt/v, por determinación del BUN al inicio y final de la misma considerándose un valor aceptable una caída de 70\%, lo cual corresponde a un Kt/v cercano o mayor a 1.3. Si a pesar de lograr una diálisis eficiente persiste el potasio sanguíneo elevado se debe descartar la presencia de otros factores que pueden estar afectando la eliminación extrarrenal del potasio, siendo la

Tabla 1. Análisis de variables.

\begin{tabular}{|c|c|c|}
\hline Variable & $\begin{array}{c}\text { Grupo A } \\
\text { Trece (13) Pacientes con pseudohipercaliemia }\end{array}$ & $\begin{array}{c}\text { Grupo B } \\
\text { Cuatro (4) pacientes con hipercaliemia verdadera }\end{array}$ \\
\hline Sexo & 7 Mujeres & 1 Mujer \\
\hline Edad promedio & 47 Años & 53 Años \\
\hline Etiología de ERC & $\begin{array}{l}\text { Desconocida } 5 \\
\text { Nefropatía hipertensiva } 3 \\
\text { Glomerulonefritis crónica } 3 \\
\text { Nefropatía obstructiva } 2\end{array}$ & $\begin{array}{l}\text { Desconocida } 1 \\
\text { Nefropatía hipertensiva } 1 \\
\text { Nefropatía diabética } 1 \\
\text { Nefropatía obstructiva } 1\end{array}$ \\
\hline Pacientes con medicamentos en riesgo & $\begin{array}{l}\text { Losartan } 4 \\
\text { Enalapril } 2 \\
\text { Metoprolol } 1\end{array}$ & Losartan 2 \\
\hline Potasio sérico & $5.91 \pm 0.26$ & $5.95 \pm 0.1$ \\
\hline Potasio plasmático & $5.16 \pm 0.46$ & $5.6 \pm 0.08$ \\
\hline Sodio sérico & $138 \pm 3.72$ & $138.25 \pm 3.30$ \\
\hline $\mathrm{pH}$ arterial & $7.40 \pm 0.04$ & $7.41 \pm 0.06$ \\
\hline Bicarbonato plasmático & $21.8 \pm 2.62$ & $23.5 \pm 2.24$ \\
\hline Hemoglobina & $11.0 \pm 2.39$ & $8.57 \pm 1.7$ \\
\hline Leucocitos & $6300 \pm 1274$ & $5325 \pm 1645$ \\
\hline Plaquetas & $268000 \pm 101000$ & $187000 \pm 54000$ \\
\hline Glucemia en ayunas & $94.3 \pm 18$ & $102.75 \pm 14$ \\
\hline Consumo estimado de potasio en la alimentación & $1780 \pm 558$ miligramos/día & $1789 \pm 313$ miligramos/día \\
\hline $\mathrm{KT} / \mathrm{V}$ & $1.60 \pm 0.19$ & $1.81 \pm 0.5$ \\
\hline Electrocardiograma & $\begin{array}{l}\text { Hipertrofia ventricular izquierda (HVI): } 4 \\
\text { Hemibloqueo izquierdo: } 3\end{array}$ & HVI: 1 \\
\hline
\end{tabular}


constipación uno de los mas importantes, al igual que el consumo de medicamentos que potencialmente afecten la excreción renal de potasio (en pacientes con función renal residual) o intestinal órgano en el que se han identificado a la fecha receptores mineralocorticoides. La redistribución transcelular de potasio impulsada por estados hiperosmolares (hiperglucemia, administración de medios de contraste de alta osmolaridad) y acidosis metabólica también son importantes por tener en cuenta (1). Pero si ha pesar de excluir todas la variables anteriores persiste la elevación en el potasio sanguíneo el siguiente paso es considerar la posibilidad de pseudohipercaliemia (4-7). Esta última entidad en pacientes con ERC en terapia de hemodiálisis puede afectar a un numero importante de ellos, su etiología no es clara, pero es probable que el medio urémico genere fragilidad de los glóbulos rojos, favoreciendo su lisis espontánea y posterior liberación de potasio cuando la muestra de sangre se almacena y permite su coagulación para posterior determinación del potasio sérico. La valoración del potasio plasmático evita que las células contenidas en el coágulo liberen potasio, arrojándonos un valor más real del estado sanguíneo del potasio.

En nuestro estudio en pacientes con ERC en terapia hemodialítica encontramos que una vez excluidas todas las variables generadoras de hipercaliemia en una población de pacientes seleccionada encontramos que en $76.46 \%$ de ellos fue posible identificar pseudohipercaliemia. Este hallazgo es muy importante, puesto que evita continuar dudando de la adherencia a la dieta de los pacientes, desestimulando la prescripción de dietas muy estrictas y generalmente poco agradables, asociadas casi siempre a la administración de resinas de intercambio ionio como el sulfonato de poliestirene sódico o cálcico, las cuales aumentan notoriamente el valor conjunto de la terapia dialítica.

Se concluye que el método ideal para determinar potasio sanguíneo en pacientes con ERC en terapia hemodialítica es el plasmático.

\section{Referencias}

1. Manjarres Iglesias G, Medina $\mathbf{J} \mathbf{E}$. Transtornos de la concentracion plasmatica del potasio. En Restrepo CA, Buitrago CA, Torres J, Serna J. Nefrología Básica 2da edición. Editorial La Patria, Manizales, Colombia. 2012; 307-320.

2. Bronson WR, DeVita TV. Carbone PP, Catlove E. Psuedohyperkalemia due to release of potassium from white blood cells during clotting. $N$ Engl J Med 1966; 274: 369.

3. Fukasawa H, Furuya R, Kato A, Yonemura K, Fujigaki Y, Yamamoto T, Hishida A. Pseudohyperkalemia occurring in a patient with chronic renal failure and polycythemia vera without severe leukocytosis or thrombocytosis. Clin Nephrol 2002; 58: 451-4.

4. Sugimoto T, Kume S, Osawa N, Nakazawa J, Koya D, Kashiwagi A. Familia pseudohyperkalemia: a rare cause of hyperkalemia. Intern Med 2005; 44: 875-878.

5. Sindhu SK, Hix JK, Fricke W. Pseudohyperkalemia in chronic lymphocytic leukemia: phlebotomy sites and pneumatic tubes. Am J Kidney Dis 2011; 57: 354-355.

6. Han SW, Park JI, Yi JH, Park IK, Kim HJ. Fictitious pseudohyperkalemia due to the dilution of plasma by anticoagulant. Clin Nephrol 2009; 72: 156-157.

7. Wiederkehr MR, Moe OW. Factitious hyperkalemia. Am J Kidney Dis 2000; 36: $1049-53$. 